\title{
From Affectivity to Bodily Emanation: An Introduction to the Human Vibe
}

\author{
Jason Del GANDio
}

This essay is a phenomenological investigation of bodily emanation. In everyday discourse, bodily emanation is often referred to as a vibe, the vibe, vibes, vibrations, or some variation thereof. The cultural landscape is saturated with references about the vibe: well-known song titles like "Good Vibrations" by the Beach Boys and "Positive Vibration" by Bob Marley; movie titles like Vibes (Columbia Pictures 1988) and Vibrations (Dimension Home Video 1995); Vibe Magazine, which reports on hip-hop culture; a line of cars by General Motors called the "Pontiac Vibe"; dictionary entries filed under "vibes" on freedictionary.com, yourdictionary.com, and urbandictionary.com; the British sports website sportsvibe.co.uk; the online neighborhood search guide mqvibe.mapquest.com; an annual musical festival entitled "Gathering of the Vibes"; and everyday references like "that was an intense vibe" and "I feel a bad vibe in here." There are also lesser known references like Michel Foucault's description of a particular experience as "immensely vibratory" (Macey 254) and Che Guevara's description of Fidel Castro's speaking abilities:

Fidel is a master at this; his particular mode of integration with the people can only be appreciated by seeing him in action. In the big public meetings one can observe something like the dialogue of two tuning forks whose vibrations summon forth new vibrations each in the other. Fidel and the mass begin to vibrate in a dialogue of growing intensity which reaches its culminating point in an abrupt ending crowned by our victorious battle cry. (314 all emphases added) 
Despite these numerous references, the vibe receives little to no sustained intellectual reflection. Scholarly journals of philosophy, communication, and psychology provide little to no research. Some thinkers such as neurophysiologist Valier Hunt (1996) and physicist William A. Tiller (1997) do address the issue. But such studies work from scientific paradigms of physics and quantum mechanics. The vibe, for these thinkers, results from the body's "bio-energy," which is the electromagnetic energy generated by the atoms and cells of the physical body. The ability to intersubjectively experience, measure, and even manipulate such bio-energy has been replicated and validated under laboratory conditions. Such accounts are related to, but not synonymous with, my project. I am approaching the vibe through a phenomenological rather than scientific paradigm. The latter begins with detached observation while the former begins with the constitution of experience. I am not concerned with the neurophysiology or quantum mechanics of the vibe. Instead, I am concerned with how we experience the vibe as an intersubjective and existential phenomenon.

The field of New Age spirituality often addresses issues related to the vibe (Dale; Gardner; Peirce). But these discussions lack analytical rigor and often collapse disparate phenomena (such as auras, halos, chakras, and alternative healing practices) into a single explanation resembling something like animism. That is not my project. The vibe is its own phenomenon and must be accounted for on its own terms; it must be granted its own philosophical explanation.

At first glance, Teresa Brennan's work on the "transmission of affect" (2004) appears to be similar to the vibe but, in the end, they are not the same. Brennan elucidates how emotions (love, guilt, envy, joy, etc.) literally pass from one person to another; how one individual can experience the same emotions as another. Brennan relies heavily upon 
psychoneuroendocrinology to explain this transmission. For instance, a friend of mine begins to cry and her body undergoes hormonal changes that release pheromones into the atmosphere. My body's olfactory capabilities then ingest those pheromones, setting off hormonal, biological, physiological and, ultimately, emotional and psychological chain reactions. Now, I, too, am crying. This transmission of affect, while awfully interesting, is not the same thing as a vibe. The vibe is not a chemical interaction. Instead, it's an actual feeling that literally emanates from the body. And that feeling is its own phenomenon that cannot be reduced to physiological chemicals.

It should be noted, too, that some people might think of "the vibe" as a metaphor for emotion, intuition, or some other ambiguous experience or feeling. It is true that "the vibe" is commonly used as a catch-all phrase to describe everything from inanimate objects to visual images to musical sounds to extrasensory perception. But this "kitchen sink approach" hinders our ability to properly understand the actual phenomenon. If "the vibe" refers to everything, then it really refers to nothing.

To avoid these various problems, I begin with something that is both specific and universal: the human body. I argue that the body is the site and source of vibrational experience. The vibe is not something outside of our embodied experience; instead, we experience the vibe in and through our bodies. I therefore argue that the vibe should be rearticulated as bodily emanation: human beings emanate feeling that is experienced by and through our bodies.

The following pages are divided into two main sections and a conclusion. The first section grounds my study of bodily emanation in phenomenological accounts of the body. I begin with Edmund Husserl's notion of affectivity. Husserl argues that the body's pre-reflective relationship to the surrounding environment involves a matrix of affects and responses- the body, prior to any conscious positing of the world, is attracted to and repelled from particular 
environmental data and phenomena. Such affectivity demonstrates that the body is in direct contact with both the environment and other bodies before and still after conscious awareness and understanding. I then introduce Eugene T. Gendlin's notion of the sentient body. Gendlin follows in but also advances Husserl's project by arguing that we can think along with the body's own affectivity. Gendlin demonstrates his point by extending Maurice Merleau-Ponty's "primacy of perception." For Gendlin, the body is an experiential organism that responds to itself and its environment in a sentient manner. Our bodies feel themselves and the world. Such sentience operates prior to and after any perceptual having-of the world. Gendlin thus argues that sentience rather than perception is the primordial basis of our bodily-being-in-the-world.

The second section continues this line of thinking: Our bodies do not simply respond in a felt manner, but also solicit feeling from one another. This solicitation of feeling is the basis of bodily emanation. I elucidate bodily emanation on two levels of experience: the pre-conscious and the conscious. The former is the realm of primordial solicitation-our bodies summon emanation from one another in a continuous, multilateral manner that precedes conscious control and recognition. The latter is the realm of conscious emanation-we can and often do send, project, and direct particular vibes for particular purposes. We emanate sympathy during funerals, joy during weddings, excitement during sporting events, eagerness during first dates, etc. This is the realm of experience that most people think of when they refer to "the vibe."

I conclude the essay by briefly outlining three implications of this study: (i) re-specifying the vibe as bodily emanation simultaneously concretizes and expands our everyday language; (ii) bodily emanation advances an intellectual tradition that began with Edmund Husserl; and (iii) bodily emanation introduces a new avenue of phenomenological research that necessities more thought and discussion. 


\section{Phenomenology of the Body: From Affection to Sentience}

My approach to bodily emanation begins with Husserl's phenomenological account of the body. In Analyses Concerning Passive and Active Synthesis (2001), Husserl explicates, among other things, the body's responses to and interactions with its surrounding environment. Husserl refers to this process as "affectivity," which is:

the allure ... the peculiar pull that an object given to consciousness exercises on the ego; it is a pull that is relaxed when the ego turns toward it attentively, and progresses from here, striving toward self-giving intuition, disclosing more and more of the self of the object, thus, striving toward an acquisition of knowledge, toward a more precise view of the object. (196)

Husserl's Analyses makes many different distinctions and outlines various levels of affection in both the reflective and pre-reflective realms of experience. This is neither the time nor place to review all of the complexities. Suffice it to say that, at the most basic level, "affection" is the awakening of attention toward an object by virtue of the object's solicitation of my attention (196-221). For example, my body, in so far as it is inserted into an environment of definitive objects, is drawn to particular aspects and features that constitute and actually enable a field of experience. That field-of-experience comes into relief_-becomes prominent for me — as my attention is drawn toward particular details, data, and phenomena. The environment and my experience are thus co-constituted in that each gives definitive shape to the other-i.e., each side affects the other. This co-constitutive process is not based solely upon that which is present to, but also through that which is absent from, my immediate perceptual experience. Something becomes prominent only insofar as a field of non-prominence supports it. In other words, my attraction to particular phenomena simultaneously diverts my attention away from other phenomena; each is constitutive and operative. For instance, I cannot simultaneously see both sides of my hand. I can turn my hand sideways to glimpse both sides, but then I am able to see 
only the thumb side or the pinky side, not both. To see one thing is to not see something else; and what I am attracted to and notice in this moment may be different from that of past and/or future moments.

The affectivity of the body-environment relationship is not simply the constitution of awareness in the most general sense, but also, and more importantly, the very genesis of experience. As Husserl says, "when there is no affection coming from the diverse objects, then these diverse objects have slipped into sheer nightfall, in a special sense, they have slipped into the unconscious" (221). In other words, the affective allure between my body-and-itsenvironment enables the very possibility of experience. My body and the environment are "coawakened" through the affective allure that each exerts on the other. This insight highlights the basis of phenomenology: My body and the world are not as separate and autonomous as they first appear; instead, my body and the world are two different correlates of an interconnected, processual totality.

Such affection-and-awakening occurs at a pre-reflective realm of experience-i.e., a level of experience that precedes conscious thought, judgment, and decision making. Reflective and pre-reflective realms of experiencing can be discerned from one another during basic, everyday activities. For example, I may walk into a congested bank lobby and look around to see which line is the shortest. After consciously reflecting upon the particular possibilities, I move to a specific line, but soon discover that it is the slowest one! I then stand there contemplating whether or not to move to another line. I even ask the person in front of me for advice. But my embodied, pre-reflective experiencing is operating long before these conscious observations and choices. A plethora of phenomena and events affectively rival for my attention: the clocks on the walls; the color and design of the floor; the rainy weather outside; the other customers mingling 
about; my lack of sleep the previous night; and even the appointment I have to catch in twenty minutes. All of these affect my relationship to and movement within this environment. As Anthony Steinbock states in the "Translator's Introduction" to Husserl's Analyses:

... in the living present there is not just one single ray of affective force on me, for many things exercise affections and rival for my attention to some degree or other. In a field of affective tendencies that rival one another for attention, some will be more or less significant than others, and these rivalries can occur within the same field or across sense fields. Even though there is an affective force, it is not necessary that it draw my attention to it; it may only be 'perceived' in a passive attention as it knocks at the antechamber of the ego; it may not yet or ever achieve an active attention, cognitive or otherwise. (xlix, emphasis in the original)

This pre-reflective affectivity can be distinguished from my reflective choice making by sifting through my experience of any given situation. I might be standing in the bank lobby when I suddenly realize what affected my decision to stand in a particular line: it was the teller's friendly face that attracted me to this (slower) line, and it was the angry looking teller a few windows down that detracted me from that (faster) line. My body was pre-reflectively attracted to and detracted from these situational conditions. This is the nature of the "affective competition" that the environment exerts on my body. But this competition is reciprocal in that my body participates in and contributes to the overall process. My body is not just affected by, but also affects, the environment and other bodies. This might explain, for instance, why no one is standing in line behind me. My disgruntled, unpleasant body acted as a repellent for the other bodies. This could be true even if I am not overtly and outwardly angry. My inner attitude, despite my best efforts, expresses itself through micro behaviors that are too fine to be consciously noticed by the other customers. But their bodies pre-reflectively respond and adjust to my micro behaviors. 
This example highlights the process by which our bodies pre-reflectively orient themselves to objects-in-the-world according to their own internal sense-constitutions (Steinbock 153-57). The body, prior to any conscious decision-making, takes up relationships to other objects in order to attain a better sense of those objects; the body continually orients itself to its surrounding environment in order to attain greater clarity and insight of its situation. According to Husserl, "'What is there' [what appears] is decided upon from the standpoint of the matter, by itself, and in making a decision, the ego follows the decision on the part of the matter" (91). In other words, the body operates according to an intelligence and logic of its own as it traces out the trajectory set forth by the object. That intelligence is grounded in the body's affective relationship to the surrounding environment.

Many theorists have expanded upon and advanced Husserl's account of the body. ${ }^{1}$ Rather than traversing this entire tradition, I want to focus on Eugene T. Gendlin and his notion of the sentient body. Gendlin's first book, Experiencing and the Creation of Meaning: A Philosophical and Psychological Approach to the Subjective (1997), investigated the relationship between embodied experience and symbolization. He argued that the body is a concrete mass of ongoing experiencing that displays and responds to signs and symbols in a sentient manner. This embodied sentience is not some amorphous feeling or emotional response. Instead, it is an ontological feature of embodiment. To be human is to be embodied and all embodied creatures implicitly feel their environments. The human environment also includes signs and symbols. But Gendlin argues that the human environment is not reducible to or completely determined by signs and symbols. Instead, there is a level of experience that precedes and exceeds symbolization. Gendlin, via phenomenology, grounds that level of experience in the constitutive relationship between the body and its environment (i.e., affectivity). 
Although Gendlin follows phenomenology, he also argues for a more radical starting point. For example, in "Primacy of the Body, Not the Primacy of Perception" (1992), Gendlin extends Maurice Merleau-Ponty's notion of the perceptual body. For Merleau-Ponty, the body is a synaesthetic organism that experiences, interacts with, and co-constitutes, its surrounding environment: the body begins, first and foremost, as a unified sensorium that is in and of the world; and then, only secondarily, does that body experience a separation of the five senses. This sensory separation provokes and is provoked by a perceptual-and-experiential distancing between the subject and the object, between the individual and the world. Merleau-Ponty refers to this distancing as the phenomenon of "depth." Without depth, we would be unable to resist absorption into the object, into the environment, into the world. As Merleau-Ponty states:

More directly than the other dimensions of space, depth forces us to reject the preconceived notion of the world and rediscover the primordial experience from which it springs: it is, so to speak, the most 'existential' of all dimensions, because . . . it is not impressed upon the object itself, it quite clearly belongs to the perspective and not to things. Therefore it cannot either be extracted from, or even put into that perspective by consciousness. It announces a certain indissoluble link between things and myself by which I am placed in front of them, whereas breadth can, at first sight, pass for a relationship between things themselves, in which the perceiving subject is not implied. By rediscovering the vision of depth, that is to say, of a depth which is not yet objectified and made up of mutually external points, we shall once more outrun the traditional alternatives and elucidate the relationship between subject and object. (Phenomenology 256)

Gendlin appreciates this analysis, but he wants to move further in the direction that Merleau-Ponty begins. Gendlin argues, in brief, that the body-raw and naked-exists and functions prior to perception. As he states:

To begin philosophy by considering perception makes it seem that living things can construct reality only through perception. But plants are in contact with reality. They are interactions with their environments, and that is not lost just because ours also have perception. On the contrary, for us that functions in many additional ways. Animal bodies - including ours - sense themselves, and thereby sense the interactional living we 
are. In sensing themselves, our bodies sense our physical environment and human situations. The perception of colors, smells, and sounds is only a small part of this.

Our bodies sense themselves in living in our situations. Our bodies do our living. Our bodies are interaction in the environment; they interact as bodies, not just through what comes with the five senses. Our bodies don't lurk in isolation behind the five peepholes of perception. ("Primacy" 344, all emphases in the original)

Like Merleau-Ponty and other phenomenologists, Gendlin argues for a layer of experience that is primordial to language and the individual, formulated ego. But Gendlin is also arguing — and this is the uniqueness of his project— that we can think along with this primordial environmental interaction. If our bodies are this environmental interaction, then we can allow our bodies to think this interaction. Gendlin describes this thinking-with-the-environment as a felt-bodily sense; our bodies sense, in a felt, sentient manner, their surrounding environments.

Gendlin's method for thinking with the sentient body is referred to as "focusing" (Focusing, Focusing-Oriented). The purpose of this method is to attune our felt-bodily sensing to our surrounding situations. Focusing was originally developed as a form of psychotherapy, thus allowing us to resolve personal and/or interpersonal issues. Focusing begins by quitting your psychological noise and clutter. You then ask yourself a question and allow your body to respond. The response is experienced as a felt bodily-shift. Something on the "inside" of your body shifts, moves, and/or "speaks back to you." Such embodied-shifts indicate that that is the issue to be addressed and unpacked. But the experience of that is not the actual emotion or trauma in question. Instead, the experience of that (the body-shift) is your body's way of telling you which emotion, trauma, or issue you need to address. These subtle distinctions can be extremely confusing and can raise numerous theoretical questions. This current essay does not allow for a complete elucidation of Gendlin's philosophy. Suffice it to say that there is your body's ongoing felt-sensing, and then there is your body's felt-sensing that responds to particular 
emotions, traumas, and issues. Your felt-bodily sensing lets you know what issues you need to address and "focus" on.

Focusing is not reducible to psychotherapy. For Gendlin, felt-bodily sensing is our primordial way of being-in-the-world and focusing allows us to better attend to that sensing. Focusing is a general mode of thinking-the-body-situation; it enables us to sense our embodied response and then to further think with and from that response. That felt-response helps us to sense and then to overcome various impasses in our thinking and choice-making. This is applicable to a wide range of experiences: the poet needs another metaphor; the philosopher needs another argument; the mathematician needs another formula; and the logician needs another line of reasoning. In each case the person feels lost, as if there is no way to bridge the present thought with the needed future thought. But we can attend to our felt-bodily sensing and enable our bodies to respond to the demands of the situation. The next thought, line, or argument then comes forth. Numerous lines and thoughts usually come forth together, and we must then sift through them, sense the exactness of each, and make a choice. For Gendlin, this is the basic nature of all human epistemology; focusing, as a general method for thinking, therefore applies to most if not all human situations.

In many ways, focusing allows us to think with the "affective allure" that exists between our bodies-and-the-world. As Husserl says, our bodies move themselves in their striving for clarity and precision of the world. Focusing enables us to think with this self-moving process. In this sense, then, focusing is not an abstract thinking-about the body-world nexus. Instead, focusing is a concrete thinking-with that nexus; it asks you to think with and from rather than about your body-situation. This is not to disregard critical, analytical thought. That is always important. But even that kind of thinking can be done with and through felt-bodily sensing. You 
attune yourself to your felt-sensing and then allow your body to tell you what and how to think about whatever issue you are currently addressing. This can be difficult to comprehend because most people separate the mind and body. But Gendlin, by way of the phenomenological tradition, challenges this perspective: the mind is the body thinking about its own situation. The body can and does think, and we can therefore learn to think further with and from the body. As we do that we can begin to sense ourselves, each other, and our world in a different manner. The world takes on a different kind of sensing - it becomes a sentient enterprise. This sentience is not an emotional or sentimental gesture. It's an embodied orientation grounded in felt-sensing. ${ }^{2}$

I appreciate and even applaud Gendlin's philosophy. However, I believe that there is more to our sensing and embodied feeling than he articulates. I agree that the body is a sentient entity, but that sentience is not simply a responsive order; the body does not simply respond to itself and the world in a sentient fashion ("Responsive"). The body also solicits sentience from other bodies. Such sentient solicitation is the basis of bodily emanation.

\section{Bodily Emanation}

Bodily emanation is the actual and tangible feeling that our bodies solicit from one another. It is a mutually provocative solicitation of embodied sentience. Our bodies do not simply transmit or radiate feeling to, but also evoke feeling from, each other. This is an important distinction. The single, isolated body can and does consciously project particular vibes for particular purposes. But the individual body does not simply emanate vibrations in an outward, unilateral manner. If it did, then there would be no vibrational interconnection between our bodies - our bodies would emanate outward into a dead, empty space. And if that were the case, then there would be no attraction and repulsion, no entwinement, no intercorporeality. In 
brief, it would not be very "phenomenological." On the contrary, our bodies preconsciously elicit vibrations from one another in an ongoing, multilateral fashion. It is a mutually solicitous process that occurs before and beyond our conscious control. In many ways, then, bodily emanation is an impersonal phenomenon. Just as the body breathes, digests, defecates, grows, changes, and ages on its own accord, so, too, does it elicit-and-emit feeling. Bodily emanation therefore precedes and exceeds my own personal subjectivity. But we can (and often do) turn our attention to bodily emanation in an active, conscious manner. This allows us to send, project, and direct particular vibes for particular purposes. We can also consciously attend to the vibes of others-e.g., a person's vibe may feel cold, intense, dangerous, intimidating, welcoming, happy, etc. Different people are of course differently attuned to bodily emanation-some people are very attuned while others are not (consciously) attuned at all. But regardless of one's level of attunement, bodily emanation is an ever-present phenomenon permeating all human interactions: it is an ongoing, impersonal phenomenon that we can actively attend to, thereby allowing it to function more prominently within our lives.

\section{(a) Two Realms of Bodily Emanation}

Bodily emanation occurs on at least two levels of experience - the preconscious and the conscious. These levels correspond to the traditional phenomenological designations of prereflective and reflective experiencing, respectively. I prefer the terminology of preconscious and conscious because it sets up a third realm of experience, which I refer to as post-conscious. This current essay does not allow me to properly elucidate this third realm. Suffice it to say that post-conscious emanation occurs when we have sufficiently attuned ourselves to the ongoing solicitation of bodily emanation. At this level of experience, we willfully allow our bodies to be 
pushed and pulled in accordance with their own vibrational attunements. At that point bodily emanation acts as an existential guide. But for now, I turn to the two basic realms of experience.

\section{(1) The Preconscious Level}

Our bodies solicit emanation from one another in an ongoing, primordial manner; it is a continual and ceaseless process without interruption. This primordial summoning of emanation is not a conscious endeavor. We do not have to think about it for it to occur; it happens on its own accord. We are thus rarely if ever motivated to reflect upon it. But we can, as the phenomenological tradition suggests, "turn toward it" and bring it into conscious relief. As we do so, we begin to understand the primordiality of bodily emanation: just as our bodies are affected by and awakened to objects and environments, so, too, are our bodies affected by and awakened to one another's vibrational solicitations.

I may attend a musical concert, for instance, and be surrounded by hundreds or even thousands of emanating bodies. The body — my body — is perpetually engaged in the process of solicitation. At the conscious level, I am most likely aware of and actively attuned to the people seated around me and the musicians on stage. I am looking at and focusing on these people and therefore consciously attending to their emanating bodies. But there is also a preconscious level to this whole experience. That preconscious experiencing begins as a collective process: all of our individual bodies are evoking a collective vibe. I can then turn my attention toward it and thereby consciously feel that collective vibe. I might even mention it to my friends: "the vibe here is great!" and "this is an intense vibe!" I not only feel the vibe of this or that person, but also the overall vibe that is being generated between us. I cannot actively attend to the emanation of each individual body; human consciousness is not structured in such a way. But my body is preconsciously attuned to the subtleties and particularities of each emanating body. This 
preconscious experiencing is enabled through two correlative features: gravitational pull and navigational guidance.

Gravitational pull is a vibrational attraction that is evoked-and-emitted between our preconscious bodies. While at the concert, for instance, I notice that my body keeps turning toward a particular direction that is away from the stage. This is bewildering since the stage is the central location of action and entertainment. But every time I reposition my body toward the stage, I inevitably find myself turning toward this other direction. I then notice someone joyously dancing off in the distance. It then dawns on me that my body is attracted to, and is thus adjusting itself toward, this person's bodily emanation. There is some type of gravitational pull between my body and that body. In no way was I consciously aware of this single individual dancing in the distance. But the vibrational correlation between our bodies exerts a gravitational pull between us.

This particular description is obviously similar to Husserl's notion of affection. But there is a difference: affection is constituted through the body's pre-cognitive engagement with the "objects of the world" (broadly conceived), while emanation is constituted through our bodies' evocation of feeling from one another. These are two different aspects of experience. Consequently, we should resist the urge to interpret either emanation or affection through the lens of the other. For example, someone might argue that my description of bodily emanation is simply a different way of describing Husserl's affection, or, conversely, that Husserl's affection is simply a different way of describing bodily emanation. Either move is too reductive and misses the fullness of each experience. Both affection and emanation are part and parcel of the human condition, and neither one should be reduced to the other. Gravitational pull therefore describes a vibrational attraction between bodies. 
Navigational guidance is similar in that it registers as a vibrational attraction, but it also involves a vibrational repulsion-it pushes-and-pulls us toward and away from one another. Continuing the example from above, it is not possible for me to consciously attend to the individual bodies standing on the other side of the concert stadium. However, my body and those other bodies are preconsciously soliciting emanation from one another. This preconscious solicitation involves navigational guidance: We will be navigated toward one another if there is an attraction between our emanating bodies, and we will be navigated away from one another if there is a repulsion between our emanating bodies.

This pushing-and-pulling process is influenced by the physical proximity between our bodies. The farther the distance, the farther the emanation must just "travel," which might result in weaker attractions and repulsions. But this is not always the case. I may, for instance, experience weaker attractions/repulsions to the people standing next to me, but experience stronger attractions/repulsions to people who are farther away. This explains why my body can be more attracted to a body that is dancing off in the distance and less attracted to a body that is dancing right in front of me. In this case, my body's attractions and repulsions are an issue of vibrational attunement: i.e., each and every emanating body is attuned to, and is influenced by, all the others. But not all bodies are equally attuned. It is an issue of degree-some are more attuned while others are less attuned. The more they are attuned, then the more they are attracted to one another. The less they are attuned, then the less they are attracted to one another. This "vibrational attunement" enables our emanating bodies to attract and repel themselves to and from one another. As the saying goes, "just go with the flow." In other words, allow your vibe to attract and repel you from particular people at particular times. 
Such a description suggests that there is never a complete break between emanating bodies; there are no absolute "dead zones" between this emanating body and that emanating body. Some level of vibrational interconnection is always summoned, and some type of pulling and guiding exists between all of our bodies. A collective vibe therefore exists, always and already.

That collective vibe has a certain kind of objectivity because it exists beyond our individual bodies. This is why we can talk about and comment on the collective vibe ("the vibe here is great," for instance). But the collective vibe is also subjective because we exist within and stand in relationship to it. That is to say, the collective vibe affects and awakens us in different ways. We may both attend the same concert and comment on a collective vibe, but you may experience that vibe as intense and exciting while I may experience it as dull and unappealing. These differences generate and are generated by the overall pushing-and-pulling of preconscious solicitation: our bodies preconsciously solicit a collective vibe from one another; we stand in relationship to that collective vibe; our relationship to that vibe then pushes-and-pulls us in different directions. This continual give-and-take between the individual and the collective creates a decentered, forever-changing cluster of preconscious solicitation.

\section{(2) The Conscious Level}

Conscious experiencing occurs when we are overtly aware of, and wakefully attend to, one another's bodily emanation. It is important to keep in mind that the preconscious solicitation of bodily emanation is a precondition for conscious experiencing. The ongoing, preconscious solicitation enables the possibility of consciously attuning to bodily emanation. The constant evocation of the phenomenon enables us to direct particular vibes for particular purposes. This 
conscious attending to and directing of bodily emanation can occur in different ways. For example, the emanation can be intentional and/or incidental.

Intentional emanation occurs when we consciously direct a particular vibe for a particular purpose. In most cases there is a direct sender, a direct receiver, and a conscious purpose. For instance, you might project a vibe of self-assuredness while walking through an unknown urban area. The purpose is to keep people at abeyance in a subtle yet confident manner. In another situation you might project a sympathetic and caring vibe when consoling a friend or loved one during an emotionally trying time. During another situation you might emanate an open and inviting vibe when meeting new people in the hopes of making new friends and acquaintances. And, as a last example, you might emanate a vibe of deference, remorse, or even surprise when you are pulled over for a traffic violation. The police officer is obviously in control of this situation and s/he will decide whether or not to issue you a ticket after analyzing the various circumstances. You are aware of this, but you project a particular vibe in the hopes of subtly persuading the officer of your "innocence."

These various examples demonstrate the ability to consciously emanate particular vibes in order to achieve specific ends and goals. Other communicative phenomena - such as words, vocal tones, hand gestures, and physical appearances-are obviously important. But one's projected vibe must also be accounted for. Attempts to be supportive, sympathetic, confident, and/or innocent will often falter without emanating the proper vibe. This can be true even if the other person is not consciously attuned to the vibe. Regardless of our varying levels of attunement, each and every body is always and already preconsciously contributing and adjusting to the vibrational interaction. The vibe may be a conscious experience for me while it 
is only a preconscious experience for you. Either way, the vibe plays a constitutive role within our interactions.

Incidental emanation occurs when we are not fully attending to bodily emanation. We might be aware that bodily emanation is playing some factor in the overall interaction, but in no way are we intentionally shaping, directing, or attending to it. Incidental emanation is more of a bodily "emission" or "leakage" than a conscious emanation; it is tangential and/or accidental rather than primary and active. But incidental emanation should not be confused with preconscious solicitation. While preconscious solicitation can be attended to by noticing one's vibrational attractions and repulsions, it can never be brought into full conscious awareness. There is simply too much going on. Can one ever fully attend to the emanation of billions of bodies? No. In contrast, incidental emanation can be attended to, usually after the fact. You unintentionally emanate a vibe, which is then noticed and commented upon by you or someone else. Such incidental emanation occurs at the conscious rather than preconscious level of experience.

Incidental emanation might occur when we are deep in thought and not attending to the particularities of our emanating bodies. I might be emotionally upset and "inside my own head." In such a situation, I may unreflectively emanate a negative vibe. That vibe is not particularly intense or overwhelming, but it can be felt and recognized by others. Someone then notices this bad vibe and asks me if I am okay. I then suddenly snap out of it and realize the incidental negativity that I was emanating.

A similar situation can occur during a heated argument. Everything is fine at first. But then something pushes you over the edge and you suddenly emanate a vibe of intense anger. You are not actually saying much during the argument; most of it is communicated nonverbally. But 
here, nonverbal communication involves more than just facial and kinesthetic expressions; it also involves bodily emanation. Your vibe is cold, mean, harsh, domineering, and even piercing. It extends far beyond your body and literally takes up space, as if to push and intimidate the other person. Your vibe, simply put, is confrontational and utterly uncalled for. If this other person is a friend, relative, or spouse, you will eventually apologize and attempt to repair the situation. In acknowledging the hurtfulness of your bodily emanation, you might say something like "I'm sorry about the vibe I was giving off; it wasn't a conscious choice. My emotions unfortunately got the best of me. I'm sorry." This apology recognizes that bodily emanation can be incidental yet powerful. It is incidental because it was not consciously intended, but also powerful because it seriously affected the nature of the overall interaction. But all of this is realized only after the fact. There may have been some awareness of bodily emanation in the moment, but it was a secondary awareness. You were more focused on your distressing thoughts and emotions. Then later, upon reflection, you realize how important (or in this case, detrimental) bodily emanation was to the overall experience.

Similar examples often occur at sporting events. Perhaps you are attending a major league baseball game. Although you are with friends and having fun, the game is uneventful. It is so boring, in fact, that "the vibe is dead," meaning that there is no vibe to consciously speak of or attend to. Then seemingly out of nowhere your team's batter hits a home-run. A shot of adrenaline runs through you. Without thinking you jump up, yell, cheer and slap high-fives all around. Your body, also without thinking, emanates a vibe of excitement and cheerfulness. After a few moments you sit back down and say to your friends, "Wow, that sure got the vibe going!" Neither you nor anyone else consciously intended to emit such an energetic vibe. Instead, it was a moment of incidental emanation. The stadium was lifeless and everyone was bored. But the 
batter suddenly hits a home-run. The crowd witnesses the hit, recognizes its meaning (your team is now winning), and becomes high on physical adrenaline and emotional excitement. This physiological-and-psychological condition brings with it a corresponding vibe. In this moment, the vibe very much becomes a conscious phenomenon; everyone is aware of it. That vibe may actually continue throughout the rest of the game and move from an incidental to an intentional phenomenon. This is particularly true at the end of a close ballgame. The score is tied in the bottom of the ninth inning. The crowd is both exhausted and exhilarated. The last batter is at the plate and it's a full count. The fans are on their feet consciously emanating a vibe of eager excitement. The batter steps up and, feeling the vibrational support and expectations of the crowd, is able to better focus and "get in the zone." That's what great athletes live for. Then, true to form, there it is: The winning home run! The crowd goes wild and the stadium is electrified with a collective vibe of celebration. In such moments, the vibe is ostensible and tangibleeveryone can feel it.

This example highlights the correlativity of intentional and incidental emanation. There is no clear, wholesale break or separation between the two. Instead, each is relative to the other. The vibe might be either intentional or incidental in one moment, but just the opposite in the next. It is an issue of being more or less aware of and receptive to bodily emanation. In one moment you incidentally emanate a particular vibe. But then something occurs within your field of experience that calls you to a greater level of attention. You are then fully aware of your emanating body and begin to direct your vibe with more (or even less) conscious purpose.

\section{(b) Three Features of Emanation}

The preceding sections focused on the conscious and preconscious realms of bodily emanation. The following sections focus on three general features of bodily emanation: 
magnitude, intensity, and temperament. These features function within both realms of experience. For the sake of simplicity, I will first describe each feature at the level of conscious emanation. I will then briefly describe how these features function at the level of preconscious solicitation. It should be noted, too, that these "general features" are not the last word on bodily emanation. Other features can and should be elucidated in future essays and/or by other thinkers. As the title of the essay states, this is an introduction to bodily emanation.

\section{(1) Magnitude}

Magnitude is the amount and quantity of feeling that an individual body emanates; it is the amount of bodily force, energy, and/or presence that is emitted by one particular body and felt by another particular body. The word "amount" is not entirely accurate since no actual amount can be clearly categorized, classified, or mathematically represented. There is, to the best of my knowledge, no scientific procedure for measuring an amount or quantity of emanation. There are devices for measuring electromagnetic energy, and studies successfully demonstrate that the human body does emit such energy. But as stated in the introduction, bodily emanation is not reducible to electromagnetism. The quantity of magnitude therefore lends itself to qualitative description: the quantity of emanation might register (be experienced) as high, low, strong, weak, powerful, dynamic, etc. Such qualitative descriptions are relative to each person who feels and articulates the magnitude. What I feel and articulate as a "high" magnitude of emanation someone else might feel and articulate as a "low" magnitude. This is not to say that intersubjective agreement never occurs. Groups of people often experience and agree upon the particular force and presence of this or that vibe. But in general, detecting and responding to vibrational magnitude is relative to our unique bodily dispositions. 
Magnitude can be experienced on different levels and in different contexts. You might pass someone on the street and acknowledge that the person's vibe was very strong. A teacher might state that the collective vibe of the students today was weak or even dismal. A team of athletes might tell one another to "get the vibe going"-i.e., they must increase the magnitude of their collective vibe. A dance instructor might chastise her troupe for not emanating enough energy. And a doctor or nurse might comment upon an ill patient's low magnitude of emanation.

\section{(2) Intensity}

While magnitude refers to an amount of feeling, intensity refers to the strength of vibrational connection between two or more bodies; it is the depth and degree of connection that is felt between our bodies.

Intensity can be illustrated by the strong vibrational connection between strangers. You are in a crowded room and know only one other person who is introducing you to everyone else. You are then introduced to another stranger, but this time it is different. There are the basic introductions and salutations, friendly gestures back and forth. But there is something more to this interaction. It is as if the two of you have been best friends, always and already, and are now finding one another after a decades-long hiatus. The vibrational intensity is not just tangible, but thick and intoxicating. You may even experience physiological reactions to the interaction-the hairs on your arms stand on edge, the back base of your neck warms up, and your chest cavity tingles with feeling. Your body is responding on its own accord to its vibrational connection to this other body. This connection is not necessarily sexual, romantic, or even platonic. Sex, romance, and/or friendship may emerge from this connection, but the connection actually precedes and exceeds such socially constructed categories. Such an intense connection is partially influenced by your observations of one another's features-behavior, voice, gestures, 
etc. But deep down you know-i.e., can feel-that there is more to the connection. The degree and depth of this connection cannot be ignored or denied; it is too intense to disregard. Such vibrational intensity usually suggests that you should get to know this person, even if it's just for a brief moment in time.

Issues of intensity often arise between early dating partners. The level of intensity can be an instant turn on or turn off; it can be friendly and fun, but purely platonic; it may take a while to get going or just never materialize at all; and, in more extreme cases, it can be overwhelming and infatuating. But love and romance are not the only forms of vibrational intensity. We can experience vibrational intensities of hate, anger, envy, disgust, etc. Such connections are obviously negative rather than positive. We can even experience intensities of vibrational disconnection. Just as two magnets repel one another, so, too, can two emanating bodies. Such a repulsive relationship is best described as aversion — some kind of vibrational aversion is evoked between our bodies. We can have overt aversions to certain people, in the sense that "I do not like that person's vibe." But there are more subtle aversions in which our vibes "turn us away" from one another. These aversions highlight the fact that absolute disconnection is never truly possible since our emanating bodies are primordially interconnected through mutual solicitation.

\section{(3) Temperament}

Temperament refers to the distinguishing traits and qualities of this and that vibe, and of this person's vibe and that person's vibe. This identifying and differentiating process functions on two levels: vibrational-characteristics and vibrational-disposition.

Vibrational-Characteristics. Temperament allows us to identify and differentiate between one particular emanation and another particular emanation. Someone's body may emanate a 
feeling of "such and such" or "so and so." More specifically, a person's body may emanate a feeling of positivity, negativity, anger, joy, happiness, sadness, intelligence, ignorance, etc.

Such vibrational characteristics are typical of most if not all human interactions. A basic conversation involves many twists and turns that often come with different vibrational traits and qualities. Each word, statement, question, and response alters the "vibrational dialogue" between you and the other person. While there may be one cogent, tangible vibe between the conversation participants, there are also vibrational flows-and-fluctuations to each and every moment. These vibrational fluctuations are often subtle and unnoticed. But this changes during more acute conversational moments.

Job interviews, for example, involve many different vibrational characteristics. The vibrational characteristics of the interviewee is most likely deferential, eager, bright, and neither too strong nor too subtle. The bodily emanation of the interviewer has a greater range of possibilities since s/he is in control of the situation; the interviewer's vibe is not as important to the outcome of the situation. But that could change if the interviewer is pursuing a highly soughtafter candidate. The roles are then reversed with the interviewer's vibrational characteristics becoming not only eager and deferential, but also accommodating and invitational. Regardless of the specific roles that might play out, both people consciously craft particular vibrational characteristics and both consciously attend to the characteristics of the other.

Vibrational-Disposition. Temperament also allows us to distinguish between one person's unique bodily emanation and another person's unique bodily emanation. Vibrationaldisposition is equivalent to a felt-personality - it is a personality that a body emanates and another body feels. This is not to say that we always emanate the same disposition in the same 
way. But there is enough persistence over time and across contexts that allows us to recognize one another's vibe.

Vibrational-disposition functions in a variety of ways. For instance, I can say that "I feel close to so and so." Or, "So and so feels like a warm (or cold, happy, intelligent) person." On another level I might say that "I felt you coming up the driveway." I can also notice changes within your overall disposition and ask such questions as "are you okay" and "is everything alright?"

Vibrational-disposition functions in more subtle ways, too. I am walking down the street when someone suddenly recognizes me. This person obviously knows me since s/he calls me by name. But I cannot recall this person. I know and can feel that I have met this someone before. The vibe tells me so. The longer I stand there, the more I can feel that I have encountered this person at another time, in another place. I search for the person's name again and again as we chat. Little by little I get a better sense of this person's vibe, of this person's felt-personality. Then seemingly out of nowhere the vibe is more fully summoned and my body recalls this person's vibrational-disposition. This is so and so whom I met last year at a such and such event.

This example highlights the constitutive role that bodily emanation plays in recognizing one another. But here, the word "recognition" is not completely accurate since we are not necessarily re-cognizing, but rather, reviving and/or resummoning the vibe that had been previously evoked between us. At this level of experience, cognition (traditionally understood as a mental process) becomes a secondary rather than primary mode of knowing. In other words, bodily emanation is not simply an experiential feeling, but also a way of knowing. Bodily emanation constitutes its own epistemological paradigm. Elucidating this paradigm is not the purpose of this current essay. Suffice it to say that bodily emanation lends itself to an alternative 
form of experiential knowing that operates before and beyond the five physical senses. We can obviously see, hear, and smell one another; and if we are close enough, we can touch and taste one another. We obviously use these perceptually observable cues to recognize one another. But as Gendlin argues, the body is an organism of ongoing experiencing that precedes and exceeds its perceptual sensorium; it exists before and after the five physical senses ("How Philosophy" 14-18; "Primacy" 344). Bodily emanation is part of this pre- and post-perceptual experiencing. We therefore recognize — or in this case, re-summon—one another's vibrational-dispositions in ways that precede and exceed our perceptual grasping of the other person.

This vibrational form of knowing relates to issues of interpersonal trust and believability. For instance, we tend to rely on nonverbal behaviors more than verbal statements when deciding if we should trust someone. This occurs because nonverbal behavior is more difficult to control than verbal statements. Words and conversations are definitively marked by beginning and ending points - a person speaks, stops, listens, and then speaks again. But nonverbal behavior is continuous and perpetually observable; it can never be fully ceased or hidden and is therefore a better indicator of one's believability and trustworthiness. The same holds true for bodily emanation-it is more difficult to control than both verbal and nonverbal communication. Like nonverbal behavior, bodily emanation never ceases and can never be fully hidden - a vibe of some sort is always present. But unlike nonverbal behavior, bodily emanation can never be completely compartmentalized. A person of ill-will, for instance, can display all the proper behaviors of trust and believability while relegating nervous tics to unobservable appendages like fingertips and toes. But bodily emanation cannot be relegated in the same manner. Professional con-artists understand that there are depths, degrees, flows, and fluctuations to each and every vibrational-disposition. Con-artists thus emanate the right vibe at the right time. But any 
nervousness and/or momentary lapses of concentration are transmitted via the vibe. There is no way to compartmentalize or redirect that vibrational characteristic; it emanates from the body, fully, and is thus potentially available for others to feel and experience. Feeling that characteristic suggests that there is more to the situation than meets the eye. Your body, reacting to this negative vibrational temperament, is then called to attention: something is wrong; this person is not to be trusted; exit the situation.

\section{(4) A Matrix of Preconscious Correlations}

These features also function at the level of preconscious solicitation, with each body evoking a different magnitude, intensity, and temperament from every other body. For instance, my body and your body evoke a particular magnitude between one another. But then my body and another body evoke a different magnitude; and my body and yet another body evoke yet another magnitude, ad infinitum. This is also the case with intensity and temperament. Each and every body therefore relates to every other body in uniquely singular ways, which gives rise to a matrix of preconsciously solicited attunements. These correlations contribute to our vibrational attractions, repulsions, and congruencies. Our mutually soliciting bodies, which are continuously positioning themselves in relationship to one another, thus create a network of vibrational interdependency. ${ }^{3}$ This is, in brief, the phenomenology of bodily emanation.

\section{Concluding Remarks}

There are at least three implications that arise from this account of bodily emanation. First, it concretizes the everyday usage of "vibe" and "vibrations." The vibe is no longer a catchall phrase for some amorphous feeling or intuition. Instead, it refers to bodily emanation. Such 
specification simultaneously expands our language and focuses our attention, thereby enriching our world of everyday interactions.

Second, my investigation of bodily emanation advances an intellectual tradition. Husserl's notion of affectivity argues that the body's precognitive, prejudicative engagement with the world is operating long before the conscious mind takes notice. Turning our attention to this phenomenon highlights the very genesis of human experience. Gendlin's notion of sentience argues that we can think along with the body's affectivity. The body does not simply perceive, but also feels itself and the world. Sentience rather than perception is therefore the primordial basis of our bodily-being-in-the-world. My own study continues this tradition by arguing that our bodies do not simply respond with but also solicit feeling from one another. That solicitation is the basis of bodily emanation.

And third, bodily emanation opens up a new area of phenomenological research that demands more thought and discussion. For example, how might bodily emanation relate to charisma, face-to-face persuasion, and the affective aspects of public speaking? Do issues of race, class, gender, and sexuality affect one's experience of the vibe? For instance, how might feminine females and masculine males experience the vibe of a particular situation differently? Given such discussion, how might bodily emanation contribute to the field of cultural studies and the critical investigation of power relations and identity politics? We can also ask about the nonhuman world: Do animals solicit bodily emanation from one another? If so, do we have access to that emanation? Or is that emanation a phenomenon in its own right that necessitates its own phenomenological investigation? What about the natural world of trees, forests, flowers, etc.? My initial reaction to this last set of questions is no-bodily emanation is a human phenomenon. This explains why I have not addressed such issues in this essay. But perhaps I am 
blind to these (and other) experiences, which explains why more research and discussion are needed. One person cannot possibly delineate all the complexities of this phenomenon. At the very least, then, bodily emanation gives us plenty to think about. At the very most, it grants us a new way of understanding human experience.

\section{Notes}

${ }^{1}$ For cogent overviews of these accounts, see Welton's The Body and Body and Flesh.

2 Some people might assume that Gendlin's account of bodily knowledge ignores the problematic of habitualized behavior, particularly habits that should be changed on ethical and/or political grounds. But Gendlin's philosophy is trying to articulate a layer of bodily experiencing/intelligence that operates both before and after habituation. He is trying to develop a way to think beyond patterns, or at the very least, to think with the very process by which patterns arise. For further explanation, see Gendlin's "Thinking Beyond Patterns" and "How Philosophy."

${ }^{3}$ From here one can begin to glimpse the realm of post-conscious experiencing: sufficiently attuning our bodies to these correlations enables us to act with the various attractions and repulsions. Rather than being preconsciously subjected to primordial solicitation, we become post-consciously attuned with that solicitation.

\section{Works Cited}

Brennan, Teresa. The Transmission of Affect. Ithaca: Cornell University Press, 2004.

Dale, Cyndi. The Subtle Body: An Encyclopedia of Your Energetic Anatomy. Boulder: Sounds True, 2009.

Gardner, Joy. Vibrational Healing Through the Charkas: With Light, Color, Sound, Crystals, and Aromatherapy. Berkeley: The Crossing Press, 2006.

Gendlin, Eugene T. "How Philosophy Cannot Appeal to Experience, and How It Can." Language Beyond Postmodernism: Saying and Thinking in Gendlin's Philosophy. Ed. David Michael Levin. Evanston: Northwestern University Press, 1997. 3-41.

—. "The Responsive Order: A New Empiricism." Man and World 30, no. 3 (1997): 383411. 
- Experiencing and the Creation of Meaning: A Philosophical and Psychological Approach to the Subjective. Evanston: Northwestern University Press, 1997.

- Focusing-Oriented Psychotherapy: A Manual of the Experiential Method. New York: Guilford Press, 1996.

—. "The Primacy of the Body, Not the Primacy of Perception." Man and World 25, no. 3-4 (1992): 341-353.

—. "Thinking Beyond Patterns: Body, Language, and Situations." The Presence of Feeling in Thought. Eds. B. den Ouden and M. Moen. New York: Peter Lang, 1992. 27-189.

- Focusing. New York: Bantam Books, 1978.

Guevara, Ernesto Che. "The New Man.” Philosophy for a New Generation. Eds. A.K. Bierman and James A. Gould. New York: MacMillan Company, 1970. 312-322.

Hunt, Valerie V. Infinite Mind: Science of the Human Vibrations of Consciousness. Malibu: Malibu Publishing Co., 1996.

Husserl, Edmund. Analyses Concerning Passive and Active Synthesis: Lectures on Transcendental Logic. Trans. Anthony Steinbock. Dordrecht: Kluwer Academic Publishers, 2001.

Macey, David. The Lives of Michel Foucault: A Biography. New York: Vintage Books, 1995.

Merleau-Ponty, Maurice. Phenomenology of Perception. Trans. Colin Smith. London: Routledge, 1995.

Peirce, Penney. Frequency: The Power of Personal Vibration. New York: Atria Paperback, 2011.

Steinbock, Anthony. "Translator's Introduction." Analyses Concerning Passive and Active Synthesis: Lectures on Transcendental Logic. Dordrecht: Kluwer Academic Publishers, 2001. xv-lxvii.

Tiller, William S. Science and Human Transformation: Subtle Energies, Intentionality and Consciousness. Walnut Creek: Pavior Publishing, 1997.

Welton, Donn, ed. The Body: Classic and Contemporary Readings. Malden: Blackwell Publishers Ltd., 1999. ed. Body and Flesh: A Philosophical Reader. Malden: Blackwell Publishers Ltd., 1998. 